\title{
REFLEXO DAS POLÍTICAS PÚBLICAS NA SAÚDE DO TRABALHADOR: RESTAURANTE POPULAR.
}

\section{REFLEX OF PUBLIC POLICY ON OCCUPATIONAL HEALTH: POPULAR RESTAURANT.}

\author{
Nilton Penha** \\ Sonia Groisman ${ }^{n *}$
}

\begin{abstract}
RESUMO
O objetivo do presente trabalho foi questionar políticas públicas governamentais e projetar seus resultados esperados contrastando com suas possibilidades de riscos futuros e ponderar sobre o direito, o processo de saúde e doença do trabalhador e usuários do programa Restaurantes Populares. Podemos concluir que trabalhos científicos demonstram no Brasil um grande acometimento das doenças bucais e câncer oral na população, sendo seu fator de risco a placa bacteriana; a Saúde não está articulada como deveria aos demais Ministérios e Secretarias e não foram previstos lugares apropriados para os trabalhadores e usuários escovarem seus dentes dentro de restaurantes populares financiados com dinheiro público; feridas causadas por próteses mal adaptadas podem levar ao desenvolvimento do câncer bucal. A falta de planejamento com inclusão da saúde e, em especial, a saúde bucal no desenvolvimento de projetos e programas governamentais é um problema de Estado e de Governo, sendo necessária a avaliação nos demais Ministérios e esferas de governo envolvendo profissionais de saúde, de modo a serem pensadas políticas públicas que não afetem a própria saúde de um modo geral. DESCRITORES: Direito sanitário • Direito do trabalhador • Saúde bucal • Políticas públicas de saúde
\end{abstract}

\section{ABSTRACT}

The objective of this study was to question governmental policies and design their expected results, contrasting with the possibilities of future risks and ponder on the right, the process of health and illness of workers and users of the program Popular Restaurants. We can conclude that scientific studies demonstrate that Brazil has a major involvement of oral diseases and oral cancer on the population and plaque is a risk factor; Health Policies are not articulated as they should be, together with other Ministries and Departments and are not provided appropriate places for workers and users of popular restaurants to brush their teeth, a program that was financed by public money; wounds caused by ill-fitting dentures can lead to the development of oral cancer. The lack of planning with inclusion of health professionals and in particular oral health, on developing projects and government programs is a problem of State and Government acts, being necessary health professionals to assess other Ministries and government spheres in order to be thoughtful public policies that do not affect their health in general.

DESCRIPTORS: Health laws • Workers laws • Oral health • Health public policy

* Escola Nacional de Saúde Pública - Fundação Oswaldo Cruz - Grupo de Direitos Humanos e Saúde Helena Besserman

** Cirurgião-Dentista, Especialista em Saúde Coletiva pela Faculdade de Odontologia da UFRJ, Especialista em Periodontia pela Faculdade de Odontologia da UVA e Mestre em Clínica Odontológica pela Faculdade de Odontologia da UFF - E-mail: nlpj@hotmail.com

*** Professora Associada da Faculdade de Odontologia da Universidade Federal do Rio de Janeiro 
PENHA N

GROISMAN $S$

REFLEXO DAS

POLITTICAS

PÚBLICAS NA

SAÚDE DO

TRABALHADOR:

RESTAURANTE

POPULAR

242

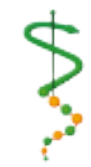

REV, ODONTOL.

UNIV. CID, SÃO

PAULO

$2013 ; 25(3): 241-$

47, SET-DEZ

\section{N T RO DUÇÃO}

A alimentação pode servir como indicador de fenômenos sociais mais amplos; a dimensão nutricional do conceito incorpora questões relativas à composição, à qualidade, à utilização biológica e à promoção da saúde, apontando a abrangência das políticas que convergem para o alcance da segurança alimentar e nutricional. Entre elas, está a Política Nacional de Alimentação e Nutrição PNAN ${ }^{1}$ (1999), como elo potencial entre o Sistema Único de Saúde SUS ${ }^{2,3}$ (1990) e o Sistema Nacional de Segurança Alimentar e Nutricional $(\text { SISAN) })^{4}$

As políticas desenvolvidas pelo Estado brasileiro, cujo objeto envolve as dimensões múltiplas da alimentação e nutrição, ganharam novo direcionamento a partir da Lei Orgânica de Segurança Alimentar Nutricional $\left(\right.$ LOSAN) ${ }^{4}-$ Lei $n^{\circ} 11.346$, de 15 de setembro de 2006, que criou o Sistema Nacional de Segurança Alimentar e Nutricional (SISAN) ${ }^{4}$ (2006).

De acordo com o conceito adotado na legislação brasileira, a segurança alimentar e nutricional - SAN - consiste na realização do direito de todos ao acesso regular e permanente a alimentos de qualidade, em quantidade suficiente, sem comprometer o acesso a outras necessidades essenciais, tendo como base práticas alimentares promotoras de saúde que respeitem a diversidade cultural e sejam ambiental, cultural, econômica e socialmente sustentáveis (Art. $3^{\circ}$ da Lei $n^{\circ} 11.346$, de 15 de setembro de 2006) ${ }^{4}$.

A Política articula sete diretrizes, que orientam a elaboração e implantação dos programas e projetos em alimentação e nutrição: estímulo às ações intersetoriais com vistas ao acesso universal aos alimentos; garantia da segurança e da qualidade dos alimentos e da prestação de serviços; monitoramento da situação nutricional e alimentar; promoção de práticas alimentares e estilos de vida saudáveis; prevenção e controle dos distúrbios nutricionais e de doenças associadas à alimentação e nutrição; promoção do desenvolvimento de linhas de investigação; e desenvolvimento e capacitação de recursos humanos.

No documento do Consea $^{5}$ (2009),
"Subsídios para a construção da Política Nacional de Segurança Alimentar e Nutricional", está proposto que o objetivo geral da PNSAN ${ }^{4}$ (2006) é assegurar o direito humano à alimentação adequada a todas e todos os habitantes do território brasileiro, promovendo a soberania e a segurança alimentar e nutricional de modo que tenham acesso regular e permanente a alimentos de qualidade, em quantidade suficiente, sem comprometer o acesso a outras necessidades essenciais, tendo como base práticas alimentares promotoras de saúde, que respeitem a diversidade cultural e que sejam ambiental, cultural, econômica e socialmente sustentáveis.

Segundo o documento do Ministério do Desenvolvimento Social (MDS) $(2008)^{6}$ e $(2005)^{7}$ a localização dos Restaurantes Populares (RP's) dentro do espaço urbano tem uma influência determinante sobre o perfil dos futuros usuários. Esse fator tem incidência independentemente da localização da unidade em nível macrorregional. Unidades situadas em regiões tidas como mais pobres como Boa Vista (RR), Manaus (AM), Teresina (PI) e Maceió (AL), não atendem necessariamente as populações mais pobres.

Dentro dessa política, a falta de inserção das práticas de higiene impede o real impacto do programa nos hábitos da população beneficiada. Parece que na maior parte das unidades a população, segundo esse estudo do MDS, tende a incorporar os RP's a suas estratégias de apropriação do espaço urbano e, em algumas unidades, esse uso está mais ligado às relações de trabalho, como é o caso de unidades situadas em zonas centrais economicamente dinâmicas (comércio e serviços, principalmente $)^{6,7}$. Nesses casos, os usuários tendem a frequentar regularmente os RP's, acompanhados de colegas de trabaIho. Em outras unidades, a localização do equipamento favorece um uso familiar ou comunitário, incorporando filhos menores, parentes e vizinhos.

Parece lógico ressaltar a necessidade de se levar em conta no planejamento do MDS $^{6,7}$ (2008) (2005) os impactos que vão além da política de segurança alimentar em stricto sensu. Como pode ser constatado pela análise geral dos resulta- 
dos, uma parcela ponderável dos usuários encontra-se fora de uma condição de extrema pobreza ou insegurança alimentar.

No que tange ao nível de instrução dos usuários dos RP's, 27\% destes chegaram até a $4^{\text {a }}$ série do ensino fundamental, os outros $47 \%$ possuem nove ou mais anos de escolaridade. A respeito da frequência, observou-se que $45 \%$ dos usuários são assíduos frequentadores desses estabelecimentos. Outra parcela, quase um quarto $(27 \%)$, afirma que frequenta esse tipo de restaurante "de vez em quando". Apenas $6 \%$ raramente comem nesses locais, e $6 \%$ estavam lá pela primeira vez. Em relação à quantidade de vezes por semana que fazem refeições em restaurantes populares, $39 \%$ dizem fazer suas refeições cerca de cinco vezes por semana em restaurantes populares. Na média dos entrevistados, a frequência de visitas é de 3,7 vezes por semana. Segundo pesquisa do IBOPE ${ }^{8}$ (2009) chegaram encomendada pelo Ministério do Desenvolvimento Social e Combate à Fome sobre o perfil dos usuários de restaurantes populares, $13 \%$ ganham mais de 3 salários mínimos, 39\% recebem entre 1 e 3 salários e $31 \%$ dos entrevistados têm vencimentos de até 1 salário mínimo.

Outra vertente dessa política destaca que, no ano de 2008, a Associação Brasileira das Empresas de Refeições Coletivas $\operatorname{ABERC}^{9}$ (2009) contabilizou $180 \mathrm{mil}$ pessoas empregadas diretamente no setor, um fornecimento de 13,7 milhões de refeições/dia pelas empresas prestadoras de serviços e um faturamento de 9,5 bilhões de reais no ano. Segundo Collares et al. ${ }^{10}$ (2007), o setor de alimentação coletiva é um setor percebido como "de passagem", em que os indivíduos ficam pouco tempo; apresenta alta rotatividade, alto absenteísmo e baixa atratividade, causados pelas limitações quanto à motivação e ao reconhecimento profissional. Nos estudos de Cavalli et al. ${ }^{11}$ (2007)e Aguiar et al. ${ }^{12}$ (2010), os Restaurantes Populares situados em Bangu, Central do Brasil, Duque de Caxias, Maracanã, Niterói e Nova Iguaçu possuíam em média 57 trabalhadores e distribuíam 3 mil refeições/dia; os de Barra Mansa, Campos dos Goytacazes e Itaboraí, 33 trabalhadores e 1500 refeições/ dia.
Quanto se amplia a visão da Política alimentar e sua repercussão na saúde bucal, a literatura demonstra que o grupo usuário de RP's carece de orientação para manutenção de uma boa saúde bucal e de um sistema de referenciamento para suprir suas necessidades bucais já instaladas, que impedem a boa digestão, fonética, estética e autoestima devido à necessidade de restaurações e próteses fiel e devidamente adaptadas. Num estudo de Marques et al. ${ }^{13}$ (2008)de caso-controle de base hospitalar, realizado entre 1998 e 2002 na área metropolitana de São Paulo, SP, o sangramento gengival, ausência de consultas com dentistas e uso regular de enxaguatórios bucais foram fatores associados com câncer oral, independentemente de tabagismo e consumo de bebidas alcoólicas. Para Rappoport ${ }^{14}$ (1997), o trauma constante também tem sido incriminado como responsável pelo aparecimento de neoplasias orais. Nesse sentido, os dentes com conservação precária, com restos radiculares ou próteses mal adaptadas, conduzem a um traumatismo crônico numa determinada região e podem ser responsabilizados no desencadeamento dessas novas formações orais. Entretanto, fica difícil estabelecer uma relação causal entre a má higiene dentária e a presença de uma neoplasia, em virtude de que a grande maioria da população em nosso país não tem acesso a uma assistência odontológica adequada e, portanto, o estado de conservação dos dentes é quase sempre muito precário. Consequentemente, a existência de restos dentários pontiagudos ou de próteses não ajustadas quase sempre está sobreposta à ocorrência de câncer bucal e outros fatores que poderiam também estar envolvidos no seu desenvolvimento são o consumo de tabaco, bebidas alcoólicas e desnutrição, dentre outros. Os agentes carcinogênicos externos, físicos ou químicos, ainda para Rappoport ${ }^{14}$ (1997), devem agir nas células mais profundas do epitélio, onde as divisões celulares ocorrem com maior intensidade, visando à reposição de células descamadas. Dessa maneira, esses agentes devem ter que encontrar alguma facilidade para atravessar as camadas mais superficiais.
PENHA N

GROISMAN S

REFLEXO DAS

POLITICAS

PÚBLICAS NA

SAÚDE DO

TRABALHADOR: RESTAURANTE

POPULAR

243
REV. ODONTOL.

UnIV. CID. São PAULO

$2013 ; 25(3): 241-$ 47 , SET-DEZ 
PENHA N

GROISMAN S

REFLEXO DAS

POLITICAS

PÚBLICAS NA

SAÚDE DO

TRABALHADOR:

RESTAURANTE

POPULAR

244

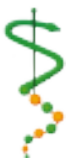

REV, ODONTOL.

UNIV. CID, SÃO

PAULO

2013; 25(3): 241

47, SET-DEZ

\section{MÉTODOS}

Esta pesquisa utilizou metodologia exploratória, através das palavras-chave utilizadas nos descritores, assim como: Direito sanitário • Direito do trabalhador • Saúde bucal • Políticas públicas de saúde. Juntamente foram analisadas as políticas governamentais adotadas nos últimos 20 anos e buscou-se uma correlação com o Estado de Direito e Saúde presente na legislação, dicotomizando os fundamentos dessas duas ciências e também se procurou discutir pontos em comum entre ambas.

\section{Do Ponto de vista do direito}

Segundo a Constituição Federal Brasileira ${ }^{15}$ de 1988, Art. 196 - "A saúde é direito de todos e dever do Estado, garantido mediante políticas sociais e econômicas que visem à redução do risco de doença e de outros agravos e ao acesso universal e igualitário às ações e serviços para sua promoção, proteção e recuperação." Já do ponto de vista do que é saúde para a América Latina, o código sanitário peruano ${ }^{16}$ (1995) diz: "A Saúde é um Bem que não pode ser renunciado juridicamente" e numa visão internacional, Resolução WHA - 23-41 da Organização Mundial da Saúde" (1970) relata: "o direito à saúde é um direito fundamental do homem".

Moraes $^{18}$ (1979), ao constatar a categoria jurídica "Bem de Personalidade", ressalta uma condição que, a seu juízo, tipifica-o: - o Bem em questão é tão correspondente ao Sujeito que este dele necessita valer-se para "lograr normal desenvolvimento de vivência social". E por lógica, caracterizado um Bem de Personalidade, reconhece-lhe imediatamente o correspondente Direito da Personalidade.

Há, pois, para Pasold ${ }^{19,20}$, uma conexão entre um Bem de Personalidade verificado como tal e o Direito da Personalidade respectivo, sendo este inalienável, irrenunciável, inextinguível (a não ser pela morte do titular), intransmissível e imprescritível, além disso, o Direito à Saúde tem conexão sinérgica com, pelo menos, três outros $\mathrm{Di}$ reitos da Personalidade: o Direito à Vida, o Direito ao Corpo e o Direito à psique.

Melo ${ }^{11}$ (1978) em seu artigo exemplifica como "Direito Político" o "conjunto de normas de Direito Público que regulam a organização e o funcionamento das instituições políticas, dispõem sobre os poderes do Estado e disciplinam as ações dos representantes desses poderes"; enquanto que "usada no plural, a expressão indica faculdades que a lei confere aos cidadãos". "Direitos Políticos" são espécies de "Direitos Individuais" e os Direitos Individuais, ainda segundo Melo ${ }^{21}$ (1978), são os Direitos Fundamentais explicitados na norma jurídica maior, sendo esta a Constituição. Mas por obviedade, percebe-se o inverso, o Direito Fundamental não constante na Carta Magna não é Direito Individual, não é Direito Político e, diante desse rigor jurídico, a Saúde é um Direito que em alguns países se consagra como Direito Individual, mas não no Brasil da Emenda Constitucional $n^{\circ} 1$, de 17/10/196922.

Discussão da importância para a saúde

Diante do exposto, sendo a saúde um direito constitucional presente na Carta Magna brasileira, podendo ser este um "bem de personalidade", podemos pensar que a saúde é um "direito político", pois, apesar das ideologias dos partidos, este deve estar nas políticas públicas tanto de Estado quanto de Governo. Dessa forma, como está presente na atual legislação, políticas públicas de Estado devem investir um percentual mínimo em saúde e programas de governos deveriam ter a presença da saúde na formulação, na organização e no acompanhamento dos mais diversos programas políticos, porque, sendo estes públicos, como são de direito fundamental e podem ser inerentes direta ou indiretamente à área da saúde, deveriam ser consultados órgãos técnicos e científicos, nas mais diversas instâncias, profissões e especialidades, pois nas políticas atuais, certamente sem a consultoria de profissionais de saúde (neste caso dos restaurantes populares, a saúde bucal) não foram consultados, sendo este um programa político e institucional de segurança alimentar e nutricional podendo gerar saúde física devido ao acesso a alimentos com valores nutricionais necessários ao desenvolvimento e manutenção das capacidades vitais. Certamente deixam de promover saúde bucal porque não foi prevista no projeto inicial, nem na organização nem 
no acompanhamento da construção de ambientes que estimulem a higiene bucal dentro dos espaços dos restaurantes populares, pois, além dos banheiros pequenos não suportarem a demanda, é preciso que estes estejam saneados de modo a proporcionar que seus usuários sintam-se à vontade para escovar seus dentes dentro dos restaurantes. Ressaltamos as expressões "saneado" e "adequado" para o "estímuIo", pois a boca é uma porta de acesso para doenças sistêmicas e não devemos permitir o acesso a ela durante a escovação dentogengival, evitando-se que uma contaminação cruzada seja proporcionada por coliformes presentes nos sanitários e, consequentemente, pelas mãos dos usuários dos restaurantes populares que fazem sua higiene nos atuais banheiros.

\section{CONCLUSÕES}

Dessa forma, urge a criação de espaços próprios para a higiene bucal, que não se- jam os banheiros atuais presentes nos 90 (noventa) restaurantes populares em todo o Brasil, mas sim a construção de "escovódromos" nos programas dos RP's.

Nos demais programas políticos é necessária a avaliação, organização prévia à implementação e também acompanhamento de profissionais de saúde, pois estes poderão avaliar tais programas sob uma nova ótica, mesmo que estes não estejam diretamente ligados à sua área de atuação. Esta é uma forma de garantir que políticas sociais e econômicas visem à redução do risco de doença e de outros agravos e promovam o acesso universal e igualitário às ações e serviços para sua promoção, proteção e recuperação, texto atualmente presente na C.F. de 1988.

Agradecimento: Ao professor pesquisador do DIHS/ ENSP/ FIOCRUZ, Luiz Carlos Fadel de Vasconcellos.
PENHA N

GROISMAN S

REFLEXO DAS

POLITICAS

PÚBLICAS NA SAÚDE DO

TRABALHADOR: RESTAURANTE

POPULAR 
PENHA N GROISMAN $S$

REFLEXO DAS

POLITTICAS

PÚBLICAS NA

SAÚDE DO

TRABALHADOR:

RESTAURANTE POPULAR
1. Brasil MdS. Portaria $n^{\circ} 710$, de 10 de junho de 1999 Diário Oficial da União - DOU; 1999.

2. Presidência da República. Lei $n^{\circ}$ 8.080, de 19 de setembro de 1990. 1990; Disponível em: http://www.planalto.gov.br/ccivil_03/leis/l8080.htm.

3. Presidência da República. Lei $n^{\circ}$ 8.142, de 28 de dezembro de 1990. 1990; Disponível em: http://www.planalto.gov.br/ccivil_03/leis/l8142.htm.

4. Presidência da República. Lei $n^{\circ}$ 11.346, de 15 de setembro de 2006. 2006; Disponível em: https://www. planalto.gov.br/ccivil_03/_Ato20042006/2006/Lei/L 11346.htm.

5. Recine E, Vasconcellos AB. Políticas nacionais e o campo da Alimentação e Nutrição em Saúde Coletiva: cenário atual. Ciência \& Saúde Coletiva 2011 16(1):73-9.

6. Secretaria de Avaliação e Gestão da Informação. Identificação de perfil e avaliação dos usuários de restaurantes populares. Brasília2008. Disponível em: http://aplicacoes.mds. gov.br/sagi/PainelPEI/Publicacoes/ dentifica\%C3\%A7\%C3\%A30\%20 de\%20Perfil\%20e\%20Avalia\% C $3 \%$ A $7 \%$ C 3\% A 3o\% 20dos\% 20 Usu\%C3\%A1rios\%20de\%20Restaurantes\%20Populares_dez2008.pdf.

7. Secretaria de Avaliação e Gestão da Informação. Levantamento do perfil dos usuários dos restaurantes populares. Brasília2005. Disponível em: http://aplicacoes.mds.gov.br/ sagi/PainelPEI/Publicacoes/Levantamento\%20do\%20perfil\%20dos\%20 usu $\%$ C3\%A1rios\%20dos\%20Restaurantes\%20Populares.pdf.

8. Ministério do Desenvolvimento Social e Combate à Fome. Perfil dos usuários restaurantes populares. 2009; Disponível em: http://www4.ibope.com.br/ opiniao_publica/downloads/opp_restaurantespopulares_set05.pdf.
9. Associação Brasileira de Empresas de Refeições Coletivas. Mercado real de refeições. São Paulo2009; Disponível em: http://www.aberc.com.br/mercadoreal.asp?IDMenu=21.

10. Colares LGT, Freitas CMd. Processo de trabalho e saúde de trabalhadores de uma unidade de alimentação e nutrição: entre a prescrição e o real do trabalho. Cadernos de Saúde Pública 2007 dez;23(12):3011-20.

11. Cavalli SB, Salay E. Gestão de pessoas em unidades produtoras de refeições comerciais e a segurança alimentar. Revista de Nutrição 2007 nov/ dez;20(6):657-67.

12. Aguiar OB, Valente JG, Fonseca MdJM. Descrição sócio-demográfica, laboral e de saúde dos trabalhadores do setor de serviços de alimentação dos restaurantes populares do estado do Rio de Janeiro. Revista de Nutrição 2010 nov-dez;23(6):969-82.

13. Marques LA, Eluf-Neto J, Figueiredo RAO, Góis-Filho JF, Kowalski LP, Carvalho MB, et al. Saúde bucal, práticas de higiene bucal e ocorrência de câncer da cavidade oral. Revista de Saúde Pública 2008 jun;42(3):471-9.

14. Rapoport A. Câncer da boca. São Paulo: Pancast; 1997.

15. DJi. Constituição Federal - CF 1988: da saúde. 1988; Disponível em: www.dji.com.br/constituicao_federal/ cf196a200.htm.

16. Ministerio de Salud. Asesoría Jurídica. Superintendencia Nacional de Servicios de Saneamiento: compendio de normas sobre saneamiento. Código sanitário del Perú: decreto ley n 17505 Lima: SUNASS; 1995. p. 235-57.

17. Organização Mundial da Saúde. Resolução WHA - 23-41 da Organização Mundial da Saúde. 1970; Disponível em: http://www.who.int/whr/2006/en/ index.html.
REV, ODONTOL. UNIV, CID, SÃO PAULO 
18. Moraes W. Direito da personalidade: estado da matéria no Brasil. In: CHAVES A, editor. Estudos de direito civil. São Paulo: Revista dos Tribunais; 1979.

19. Pasold C. Direito de saúde. Disponível em: http://egov.ufsc.br/portal/sites/ default/files/anexos/943-957-1-PB. pdf.

20. Pasold C. Da função social do estado contemporâneo ao estudo político e jurídico de um de seus segmentos: a saúde pública [Dissertação]. São Paulo: Universidade de São Paulo; 1983.
21. Melo O. Dicionário de direito político. Rio de Janeiro: Forense; 1978.

22. DOU. Emenda constitucional $n^{\circ} 1$, de 17 de outubro de 1969. 1969; Disponível em: http://www010.dataprev. gov.br/sislex/paginas/30/1969/1.htm.

Recebido em 06/08/2013

Aceito em 19/08/2013
PENHA N

GROISMAN S

REFLEXO DAS

POLÍTICAS

PÚBLICAS NA

SAÚDE DO

TRABALHADOR:

RESTAuRANTE

POPULAR 